\title{
Hospice Care
}

National Cancer Institute

\section{Source}

National Cancer Institute. Hospice Care. NCI Thesaurus. Code C15252.

The active total care of patients whose disease is not responsive to curative treatment. The goal of palliative care is achievement of the best possible quality of life for patients and their families. Control of pain, of other symptoms, and of psychological, social, and spiritual problems is paramount. Palliative care affirms life and regards dying as a normal process, neither hastens nor postpones death, provides relief from pain and other distressing symptoms, integrates the psychological and spiritual aspects of patient care, offers a support system to help patients live as actively as possible until death, and offers a support system to help the family cope during the patient's illness and in their own bereavement. (World Health Organization) 